\title{
El perfil de los miembros de las organizaciones juveniles de los partidos políticos españoles
}

\author{
The membership characteristics of Spanish political parties' youth sections
}

\author{
FRANCISCO J. ALARCÓN-GONZÁLEZ
}

Universidad de Granada

\section{Cómo citar/Citation}

Alarcón-González, F. J. (2017). El perfil de los miembros de las organizaciones juveniles de los partidos políiticos españoles. Revista Española de Ciencia Política, 45, 175-201. Doi: hittps://doi.org/10.21308/recp.45.07

\section{Resumen}

Este trabajo presenta los primeros resultados de una encuesta realizada a los miembros de las organizaciones juveniles de los partidos políticos espańoles. El texto tiene como objetivo establecer el perfil de los miembros de las formaciones políticas juveniles en función de variables socioeconómicas, demográficas y de su perfil político, para determinar las diferencias y similitudes en los perfiles de los miembros de las diferentes secciones juveniles. Además, cuando ha sido posible, se ha realizado una comparación sobre ciertas variables con la población juvenil española en su conjunto. Los datos muestran cierta homogeneidad entre los perfiles de las diferentes formaciones en razón del género y del estatus socioeconómico, pero por otro lado apuntan a diferencias en relación al ámbito religioso y su vinculación con la sociedad civil.

Palabras clave: jóvenes, perfil de militantes, organizaciones juveniles, comportamiento político.

\section{Abstract}

This research note presents the first findings of a survey conducted to members of Spanish political parties' youth sections. The text aims to establish the profile of members of youth party organizations based on socioeconomic and demographic variables as well as their political profile, in order to determine whether any differences and similarities exist in the membership characteristics of different youth sections. Whenever possible, moreover, a comparison has been made of certain variables with the whole Spanish youth population. Data shows certain homogeneity between gender and socioeconomic status profiles of the different 
organizations but, on the other hand, they point to some differences regarding the religious sphere and their link with the civil society.

Keywords: young people, party members profile, youth sections, political behaviour.

\section{INTRODUCCIÓN}

El estudio de los miembros de los partidos políticos ha sido una de las áreas clave de crecimiento dentro de los trabajos sobre comportamiento político. Destacan, más allá de las investigaciones sobre Estados Unidos, por proximidad al modelo político espańol, las realizadas sobre el Reino Unido. Los estudios de los militantes laboristas y conservadores llevados a cabo por Patrick Seyd y Paul Witheley (Seyd, 1987; Seyd y Whiteley, 1992; 2002; 2004; Whiteley et al., 1994; 2006; Whiteley y Seyd, 1996; 1998; 2002) han jugado un papel pionero y de guía que ha inspirado una agenda de investigación en Europa y Norteamérica desde 1990 (Scarrow, 1994; 1996; 2015; Mair y van Biezen, 2001; Webb et al., 2002; Pedersen et al., 2004; Bruter y Harrison, 2009; Van Huate, 2011; Van Haute y Gauja, 2015) ${ }^{1}$. Las ideas centrales señaladas en estos trabajos son la constatación de un descenso en el número de militantes y la progresiva profesionalización a nivel organizacional acaecida en los últimos cincuenta años, así como una defensa de la importancia de los militantes que siguen siendo cruciales para el funcionamiento de los partidos políticos. Tradicionalmente se ha argumentado que los militantes desempeñan importantes tareas, desde el respaldo financiero hasta el trabajo voluntario en campañas electorales. Y se ha encontrado cierta unanimidad en la presunción de que los partidos, para su propia supervivencia, necesitan reclutar y socializar nuevos miembros (Steed et al., 1998)2, necesarios para preservar el carácter de la democracia representativa en su concepción normativa actual (Dalton y Watterber, 2000; Gunther et al., 2002).

Uno de los principales canales de reclutamiento son las agrupaciones, formaciones o secciones juveniles de los partidos políticos. Estas organizaciones políticas juveniles, más allá de su importancia como agentes socializadores (Bargel, 2008), están

1. El caso español, a la luz de los datos presentes en estos trabajos, se presenta, al menos en las últimas décadas del siglo $\mathrm{xx}$, como un caso atípico en la tendencia general de descenso que acontece en las democracias occidentales (Webb et al., 2002).

2. Encontramos trabajos que sugieren un menor interés por parte de los partidos políticos en tener una gran base de afiliados desde hace algún tiempo, debido a su menor dependencia económica de los afiliados, como sí sucedía bajo la configuración del partido de masas. Por otro lado, encontramos argumentos que enfatizan el desinterés en los ciudadanos motivado, entre otros factores, por el desarrollo del Estado de bienestar que reduce el valor de los beneficios derivados de la militancia (Scarrow, 1996: 8). Para un análisis de los costes y beneficios que suponen los afiliados para los partidos políticos véase Scarrow (1994) y Méndez (2000: 158-161). 
consolidadas en la estructura de casi todos los partidos políticos (Norris y Lovenduski, 1995) desde principios del pasado siglo en Occidente ${ }^{3}$, siendo el principal espacio para la acción política juvenil institucional (Abrams y Little, 1965). Este compromiso cívico de mayor intensidad que otras formas de participación política voluntaria y el involucramiento de los jóvenes en las formaciones políticas es necesario para el mantenimiento de la concepción tradicional de la política (Bruter y Harrison, 2009; Ezpinoza y Madrid, 2010). Por otro lado, los trabajos también señalan que devenir miembro de una organización política juvenil es el itinerario indiscutible para aquellos que quieren convertirse en políticos (Abrams y Little, 1965; Recchi, 1997; Barberà et al., 2002; Hooghe et al., 2004; Bruter y Harrison 2009; Espinoza et al. 2010; Bargel, 2008). El trabajo de Hooghe et al. (2004) identifica las organizaciones políticas juveniles como uno de los centros de reclutamiento de la futura elite política. En su trabajo sobre los concejales de la región flamenca de Bélgica sitúa en ocho años la diferencia temporal en la primera posición política obtenida por aquellos que han pasado por la organización juvenil y los que no. Esta ventaja también ha sido señalada para los diputados de la Cámara Baja italiana (Recchi, 1997), francesa (Bargel, 2008) y española (Alarcón y Pérez, 2015).

A pesar de su importancia, los miembros jóvenes de los partidos políticos españoles no han sido una prioridad en la agenda de investigación y los trabajos publicados desde la transición no son muy abundantes y además existen algunos factores que limitan su poder explicativo. Un primer grupo no tiene en cuenta la organización política juvenil y se centra en el partido político sin introducir referencias sobre su composición (Tezanos, 1981; Méndez, 2000; Ramiro, 2004; Verge, 2007). Un segundo grupo, a pesar de ser más fructífero, está centrado en las elites intermedias a partir de encuestas a los delegados congresuales (Botella et al., 1979; Pitarch et al., 1980; Tezanos, 1980; Marcet, 1984; Colomé, 1992a; 1992b; 1996; 1998; Sánchez et al., 1999; Barberà et al., 2002; Baras et al., 2004; 2010; 2015; Argelaguet, 2009; Barrio et al., $2011)^{4}$ bajo una óptica de análisis de inspiración francesa y con su objeto de estudio centrado en los partidos políticos que actúan en Cataluña. Aquí destaca el trabajo Barberà et al., (2002) centrado en las formaciones políticas juveniles catalanas. En tercer lugar, y como "caso atípico", encontramos el trabajo de Bruter y Harrison (2009) que,

3. A pesar de su alta presencia en la mayoría de partidos políticos, su existencia no está libre de controversias. Por ejemplo, el Partido Conservador Canadiense tras un considerable debate interno decidió no tener sección juvenil (Cross y Young, 2008)

4. El auge de este tipo de trabajos descansa en dos circunstancias. Por un lado, estos trabajos argumentan que los congresos partidistas son el punto más alto de la vida política militante y reúnen generalmente a los miembros más activos. Por otro lado, es más fácil la conducción de una encuesta a un grupo de personas que se encuentran situadas en un espacio físico y temporal. Para el estado de la cuestión en España puede véase el manuscrito de Barrio et al. (2011). Los primeros trabajos toman la óptica de los estudios de casos y parten en se mayoría de la sociología del activismo (Duverger, 1957; Cayrol, 1974), mientras que los más actuales adoptan un enfoque comparado. 
con un enfoque comparado ${ }^{5}$, clasifica a los jóvenes miembros de las organizaciones juveniles de los partidos políticos en función de los incentivos o beneficios derivados de su participación. Esto les permite establecer tres perfiles motivacionales: social, moral y profesional. Sobre esta tricotomía analizan las percepciones y actitudes de los militantes en relación con el sistema político. A pesar de analizar a los miembros de Juventudes Socialistas (JSE) y Nuevas Generaciones del Partido Popular (NNGG) para el caso español, el texto no se detiene a mostrar las características de cada uno de los grupos ni tampoco las posibles diferencias y similitudes entre sus miembros.

Este trabajo tiene por objetivo arrojar luz sobre los miembros de las organizaciones juveniles españolas vinculadas a los partidos políticos con representación en el Congreso de los Diputados desde 1986, ofreciendo una imagen a partir de sus características sociodemográficas y políticas. Los datos disponibles posibilitan contrastar diferencias y similitudes entre los jóvenes militantes y ofrecer perfiles sociológicos de ellos. El presupuesto general de partida es la presencia de diferencias en las características sociodemográficas y políticas entre los militantes de las diferentes organizaciones juveniles en relación con los grupos principales que aportan la base social de su apoyo partidista. Si además tenemos en cuenta que la gran mayoría de jóvenes presenta un bajo interés y una escasa participación en política, podríamos suponer que aquellos que lo hacen, bajo una forma institucional de participación, presentan características que los diferencian del resto de la población juvenil. Para observar esta situación se incluyen cuando es posible datos del conjunto de la población juvenil española.

La estructura de este trabajo es la que sigue. En el primer apartado, tras esta introducción, se repasa la literatura sobre los miembros de los partidos políticos en busca de sus características y se formulan las hipótesis que contrastar derivadas de cada una de ellas. A continuación, se detallan los aspectos de mayor interés acerca de la metodología y los datos empleados. En el apartado siguiente se presentan y discuten los principales resultados empíricos, centrándonos en las características de las poblaciones objeto de estudio. Por último, el apartado de conclusiones sintetiza los resultados principales y plantea algunas reflexiones sobre las implicaciones que esta investigación puede tener para los estudios sobre los miembros de los partidos políticos y de las organizaciones políticas juveniles en particular.

\section{EL PERFIL DE LOS MIEMBROS DE LOS PARTIDOS POLÍTICOS}

La literatura sobre los miembros de los partidos políticos enfatiza la presencia de ciertas características socioeconómicas y demográficas que, por un lado, definen a sus afiliados frente a la población general y, por otro, singularizan a cada una de las fuerzas políticas. En este apartado vamos a sintetizar los principales hallazgos sobre los

5. Comprende quince organizaciones juveniles procedentes de seis países (Alemania, Francia, España, Hungría, Noruega y Reino Unido). 
miembros de los partidos políticos y establecer para cada una de las variables, siempre que sea posible, su relación con la población afiliada a las organizaciones políticas juveniles y con la población juvenil española en general.

Los trabajos apuntan a una mayor presencia masculina entre sus miembros, tanto para el caso español (Verge, 2007; Argelaquet, 2009; Baras et al., 2010; Baras et al., 2015) como en otras latitudes (Ysmal, 1985; Scarrow y Gezgor, 2010; van Haute, 2011; Muñoz Armeta et al., 2013), con escasas excepciones, como la del Partido Conservador británico entre 1980 y 1990 (Whiteley et al., 1994). En España, Baras et al. (2010) señalan que la presencia femenina es muy inferior a la masculina, con valores cercanos a un tercio de la militancia en la mayoría de los partidos políticos $(2010: 70)^{6}$. También apuntan a que las mujeres están más presentes en partidos ubicados en la izquierda del espectro ideológico, ya que estos (laboristas, socialdemócratas o comunistas, entre otros) interiorizan y hacen suyo el discurso de la igualdad entre sexos (Verge, 2007).

En nuestro país, la presencia de mujeres en las formaciones políticas ha sufrido una evolución positiva en los últimos cuarenta años. En el período comprendido entre 1976 y 1994, la inmensa mayoría de los afiliados al Partido Socialista Obrero Español (PSOE) eran hombres, si bien el crecimiento experimentado durante este período por esta formación fue progresivamente más acusado en las mujeres (Méndez, 2000: 218219). Verge señala que en el período comprendido entre 1981 y 2004, el porcentaje de mujeres en relación con la militancia total en el PSOE pasó de un 9,4\% a un $30,8 \%$, mientras que en el Partido Comunista de España (PCE)/Izquierda Unida (IU) fue de un $12,4 \%$ a un $32 \%$ en el transcurso de 1983 a los primeros años del siglo XXI (2007:166). El porcentaje de mujeres en Alianza Popular (AP)/Partido Popular (PP) ascendía al 33,6\% de sus miembros en 2004, si bien la situación de partida era un poco diferente. La afiliación femenina de AP en 1982 estaba en un 27,9 \% del total, doblando sobradamente las cifras relativas en el caso de los socialistas y comunistas. El mencionado trabajo sobre los delegados de las organizaciones juveniles también evidencia la infrarrepresentación femenina en este sector (Barberà et al., 2002: 198-200). Ante esta situación, nuestras expectativas serán encontrar: 1) una menor presencia de mujeres en las formaciones juveniles; 2) que esta se encuentre en valores cercanos a un tercio de la militancia, y 3 ) que sea superior en los partidos ubicados en la izquierda del eje ideológico.

La segunda variable objeto de atención es la edad. Las investigaciones señalan una tendencia relativamente homogénea con pequeñas diferencias. En general, los jóvenes se encuentran infrarrepresentados y los mayores sobrerrepresentados (Pedersen $e t a l$., 2004). La edad media oscila entre los 52 años de Irlanda (Gallagher y Marsh, 2004), los 59 ańos para los miembros del Partido Canadiense (Cross y Young, 2004) y los 62 años de los militantes conservadores británicos (Seyd y Whiteley, 1992; Whiteley et

6. Como se ha señalado, la población objeto de estudio en los trabajos publicados por Baras y sus colaboradores son los delegados de los partidos, especificidad esta que ha de ser tenida en cuenta para una correcta interpretación de los datos. 
al., 1994). En España, los trabajos señalan que el tramo de edad más numeroso es el comprendido entre los 35 y 50 años (Argelaguet, 2009; Baras et al., 2010), representando los menores de 35 años entre el $17 \%$ y el $27 \%$ de la formación política (Baras et al., 2015).

En el PSOE, entre 1980 y 1989, el grupo más numeroso era el conformado por la franja de 31 a 40 años, mientras que los menores de 30 años eran un $20 \%$ de los afiliados (Méndez, 2000). El trabajo sobre los delegados congresuales de las organizaciones juveniles en Cataluña mostraba una mayor presencia de los menores de 24 años en las formaciones de izquierda, mientras que en NNGG el $55 \%$ se situaba en el intervalo de 25 a 30 años (Barberà et al., 2002: 169). Si partimos de estos datos, las expectativas serán, por un lado, una militancia más joven, menores de 24 años, en los partidos de izquierda; por otro, el grupo dominante en NNGG si situaría en los mayores de 25 ańos. Hay que añadir que la edad conecta con el ciclo de vida, lo cual también tiene efectos sobre los niveles de participación política: estar casado y tener hijos supone pasar de la adolescencia a la etapa de adultez y conlleva un efecto positivo (García-Albacete, 2104). Más que una expectativa relacionada con los militantes, la edad nos permitirá ver como se distribuyen y observar si aquellas formaciones donde sus miembros son de más edad también presentan mayores porcentajes de vida en pareja e hijos.

La religión ha sido reconocida como uno de las fracturas sobre las que se articula el conflicto en las sociedades occidentales (Lipset y Rokkan, 1967). A pesar del proceso de cambio en los valores religiosos asociado a un proceso de secularización acaecido en las últimas décadas del siglo pasado y durante el siglo actual, distintos trabajos señalan diferencias remarcables en materia religiosa entre los diferentes partidos políticos españoles (véase Barberà et al., 2002; Baras et al., 2010). El porcentaje de católicos practicantes en el PP es de casi el 96\%, mientras que no llega al $5 \%$ en el PSOE y al $2 \%$ en IU. Los miembros de estas dos formaciones se consideran en su mayoría no creyentes, con un $63,8 \%$ y un $89,5 \%$ respectivamente (Baras et al., 2015). Sobre esta base, esperamos mayores porcentajes de no creyentes en las formaciones vinculadas a IU, seguido de las socialistas y en menor medida entre los miembros de NNGG. En esta última formación esperamos tener el mayor número de católicos practicantes.

Una de las características principales de separación entre la elite y la ciudadanía es el nivel educativo. Este ha sido considerado como un recurso para la participación política, incluyendo la pertenencia a partidos políticos (Verba et al., 1978; Dalton, 2005). En todos los partidos políticos españoles, la mayoría de sus miembros poseen estudios universitarios, llegando incluso en algunas formaciones a dos tercios del total (Baras et al., 2010; 2015). La expectativa será encontrar un mayor nivel formativo entre los miembros de las organizaciones políticas juveniles que en el conjunto de la población juvenil española y no apreciar diferencias significativas entre los miembros de las diferentes fuerzas políticas.

A nivel profesional, los trabajos apuntan a que los miembros de los partidos son personas activas $(80 \%)$, con un bajo porcentaje de parados, pensionistas y estudiantes (Baras et al., 2010). Encuentran diferencias en relación con los segmentos a los que se dirigen que hacen que, por ejemplo, en 1989 en torno al $80 \%$ de los afiliados al PSOE 
formaban parte de la población activa, siendo más del $40 \%$ del total obreros manuales (Méndez, 2000). Al centrarnos en los jóvenes militantes, es previsible que un gran número de ellos se encuentre todavía en su etapa formativa o que compagine esta con algún tipo de actividad laboral.

Si bien la clase social había sido un importante elemento diferenciador entre los partidos políticos en el pasado, en la actualidad estos se nutren de miembros de diferentes posiciones sociales, presentando una transversalidad que va en sintonía con los presupuestos del cath-all party (Katz y Mair, 1994). La expectativa será no encontrar diferencias en términos de clase social entre los miembros de las diferentes formaciones políticas.

Sobre el perfil político, se prevé también encontrar diferencias y similitudes entre los miembros de las fuerzas políticas. Así, por ejemplo, la presencia de diferencias puede venir de la mano de la edad de afiliación de sus miembros. La pertenencia a la organización juvenil se adquiere a los 18 ańos, aunque un gran número de ellas admite a los mayores de 14 (en el caso del JSE) ${ }^{7}$ o 16 (en el caso de NNGG) ${ }^{8}$ y se pierde a la edad de 30 ańos, aunque la mayoría de las organizaciones partidistas juveniles contempla la permanencia en la organización hasta los 30 años, inclusive. La edad puede indicar los efectos de políticas de reclutamiento o estar vinculada a vocaciones políticas más tempranas. Dogan (1999) establecía como característica del político profesional una vocación precoz por la política. El desempeño de roles de delegado o subdelegado en el aula en algún momento del período formativo también está relacionada con la práctica política posterior (Ezpinoza y Madrid, 2010) y denota un especial interés por el ejercicio de la representación. La ausencia de datos sobre esta característica no nos permite establecer una hipótesis comparativa entre formaciones o con la población juvenil en su conjunto.

En términos de asociacionismo, las investigaciones apuntan a mayores niveles entre los jóvenes militantes que entre la población juvenil española en general (Barberà $e t$ al., 2002: 205). Esta participación supone una conexión de los militantes con el entorno social y conlleva un impacto en la cultura política, al incidir el asociacionismo voluntario en la participación política (Almond y Verba, 1963). En el caso español, se observan altos niveles de asociacionismo entre los delegados jóvenes de las organizaciones políticas catalanas, con algunas diferencias entre formaciones (Barberà et al., 2002). Casi el $50 \%$ de los miembros de Juventut Socialista de Catalunya (JSC) pertenecía a dos o más asociaciones, índice que baja hasta el $30 \%$ en el caso de NNGG. En cuanto al carácter de la asociación, los delegados de estas dos formaciones presentaban valores similares de pertenencia a asociaciones culturales, mientras que el asociacionismo estudiantil solo era practicado por JSC (2002:182). La expectativa será encontrar valores altos de pertenencia asociativa. Asimismo, y en relación con los

7. Articulo 15 de los Estatutos Federales aprobados en el 24. ${ }^{\circ}$ Congreso Federal de JSE y vigentes durante la redacción de este texto.

8. Articulo 7 de los Estatutos vigentes desde el 24. ${ }^{\circ}$ Congreso Nacional de NNGG (abril de 2017). 
datos señalados, se esperan valores similares en los niveles de asociacionismo cultural y una mayor presencia de los miembros de las formaciones situadas a la izquierda del eje ideológico en las asociaciones de estudiantes.

En términos de carrera política, también sería posible encontrar diferencias. La entrada en la ejecutiva de la organización política juvenil puede verse como una de las primeras etapas de la carrera política, que consiste en pasar de ser únicamente militante de base a ser parte de la estructura de la organización juvenil. A diferencia de los partidos políticos donde el catálogo de incentivos es más elevado (Gaxie, 1977), en las organizaciones juveniles la distribución de posiciones en la ejecutiva de la organización juvenil es uno de los principales incentivos ofrecidos a sus miembros, aparte de algún incentivo de tipo simbólico (Barberà et al., 2002). La estructura multinivel del Estado, con ejecutivas a nivel local, provincial, regional y/o nacional en las diferentes formaciones políticas hace que no se esperen diferencias en el desempeño de posiciones en la estructura de la organización política.

Un segundo tipo de incentivo selectivo tiene que ver con la inclusión de los jóvenes como candidatos en los diferentes comicios electorales y en caso de éxito con el desarrollo de una posición como cargo público electo. En términos de candidaturas no se espera encontrar diferencias entre las fuerzas políticas, al concurrir en todos los procesos electorales en los diferentes niveles de gobierno. En cambio, el resultado electoral de la formación política si tiene incidencia en las carreras políticas de los jóvenes candidatos. El número de apoyos determina el mayor o menor acceso a puestos de representación política. La expectativa será una mayor presencia de jóvenes con mandatos de representación política entre los miembros de las fuerzas socialistas y NNGG, que en las formaciones juveniles vinculadas a IU, por haber recibido menos apoyos electorales.

\section{DISEÑO METODOLÓGICO: ENCUESTA A JÓVENES MILITANTES}

Para responder al objetivo general y a las preguntas formuladas en el apartado anterior, este trabajo analiza las respuestas de los miembros de las organizaciones juveniles vinculadas a tres formaciones políticas de ámbito nacional que han obtenido representación parlamentaria en todas las elecciones generales celebradas desde 1986. Se analizan las respuestas de los miembros de las organizaciones juveniles vinculadas a la ideología socialista y comunista y a los miembros de NNGG. La denominación de socialista engloba a los miembros de JSE vinculada al PSOE y a JSC, organización juvenil del Partit dels Socialistes de Catalunya (PSC). La designación de comunista está vinculada con la coalición de IU, donde operan diferentes fuerzas políticas, y que en este grupo incluye: Jóvenes IU, la Unión de Juventudes Comunistas de España (UJCE) del PCE, y Jóves d'Esquerra Verda de Iniciativa per Catalunya-Verds.

El análisis comparativo permitirá ver las características de los jóvenes militantes para determinar las posibles diferencias y similitudes en los perfiles de los miembros de las diferentes formaciones políticas, lo cual se combina cuando es posible con el 
conjunto de jóvenes españoles ${ }^{9}$. Posteriormente, el análisis se centra en tres modelos de regresión logística donde se introducen las variables sociodemográficas (modelo 1), de carácter político (modelo 2) y un tercero con todas (modelo 3), que se aplican a cada una de las fuerzas políticas objeto de atención.

La recogida de información fue un proceso que necesitó la colaboración y ayuda de la estructura interna que gestiona la vida diaria de cada organización política juvenil. Los datos provienen de las respuestas obtenidas, entre abril y octubre de 2016, a un cuestionario online alojado en la plataforma limesurvey (www.limesurvey.org), que fue distribuido vía correo electrónico entre los miembros de las formaciones. Las particularidades organizativas y de gestión de cada formación condicionaron el proceso y nos confiere cierta limitación en la comparación.

En las formaciones socialistas, el enlace fue enviado a las listas de distribución que tanto para JSE como JSC incluyen casi la totalidad de su censo. Se obtuvieron un total de 1456 respuestas. En algunas ocasiones estas no pasaron de la introducción o solo contestaron a las primeras preguntas. Esto motivó que se depurara la base de datos, lo que dio un resultado de novecientos cuestionarios validados. Este proceso se ha replicado en cada una de las organizaciones políticas juveniles. En los casos de las tres formaciones vinculadas a IU, el enlace fue enviado a partir de la lista de distribución a la totalidad de miembros de UJCE y Joves d'Esquerra Verda. El Área de Juventud de IU remitió el enlace a las federaciones territoriales de juventud y de estas a sus miembros jóvenes. El total de respuestas fue de 597 que tras la depuración quedaron en 410. En el caso de NNGG se envió el email a una selección aleatoria de mil afiliados. Se recibieron un total de 906 entradas en la plataforma online que tras el depurado dejó un total de 499 cuestionarios validados. El error muestral, para un nivel de confianza del $95 \%, y \mathrm{p}=\mathrm{q}=0.5$, en el supuesto de haber obtenido la muestra mediante el procedimiento de muestro aleatorio simple, es de 3,1\% para las fuerzas socialistas, 4,3\% para NNGG, 4,5\% para las organizaciones juveniles vinculadas a IU y $2,2 \%$ para el conjunto de la muestra ${ }^{10}$.

\section{EL PERFIL DE LOS JÓVENES MILITANTES: SIMILITUDES Y DIFERENCIAS}

\section{Exploración descriptiva}

Los miembros de las organizaciones juveniles son en su mayoría hombres. El porcentaje de mujeres es, por tanto, inferior. Los datos presentados en la tabla 1 están en

9. Para ello, usamos el estudio CIS 3145 (postelectoral Elecciones Generales) realizado entre el 2 y 21 de julio de 2016. Se selecciona a los encuestados de edad igual o inferior a 30 ańos, lo que supone una muestra de 1009 casos.

10. Para el cálculo se ha tomado como $\mathrm{N}$ el censo de militantes de cada organización política juvenil. Dicha cifra es conocida por el autor del texto. Algunas organizaciones juveniles han mostrado su deseo de que la misma no sea difundida. 
sintonía con los de los trabajos sobre miembros de los partidos comentados con anterioridad. Entre los jóvenes militantes socialistas y populares, la presencia de mujeres supone el $40 \%$ de la militancia, mientras que entre los comunistas contempla un $30 \%$ de sus bases. Esto nos hace rechazar la hipótesis de una mayor presencia en los partidos de izquierda. En cualquier caso, para las tres fuerzas políticas, a la luz de estos datos, la presencia de mujeres en las organizaciones juveniles es muy inferior a la masculina y, al menos como en los partidos políticos, se mantiene en un tercio del total de la militancia.

Entre los jóvenes militantes encuestados, un $60 \%$ se encuentra en la franja de edad 18-24 ańos, porcentaje similar al encontrado para los delegados de las formaciones juveniles catalanas (Barberà et al., 2002). Los socialistas presentan un mayor equilibro en la edad de sus miembros, ya que el porcentaje de militantes de edad inferior a 24 años es similar al de más de 25 años. Las bases de las otras dos fuerzas políticas son más jóvenes, sobre todo entre los miembros de NNGG, donde más de un $80 \%$ tiene una edad inferior a 24 años. En el caso de las organizaciones vinculadas a IU, dos de cada tres miembros tienen menos de 25 ańos.

TABLA 1.

Perfil sociodemográfico (en \% De Respuesta afirmativa)

\begin{tabular}{|c|c|c|c|c|c|c|}
\hline & & Socialistas & NNGG & Comunistas & $\begin{array}{c}\text { Total } \\
\text { jóvenes } \\
\text { militantes }\end{array}$ & $\begin{array}{c}\text { Población } \\
\text { juvenil }\end{array}$ \\
\hline SEXO & MUJER & 40,6 & 36,5 & 28 & 36,6 & 50,2 \\
\hline \multirow{4}{*}{ EDAD } & $14-17$ & 6,7 & 1,4 & 9,5 & 5,9 & * \\
\hline & $18-24$ & 48,1 & 82,4 & 59,7 & 60,1 & 49,1 \\
\hline & $25-30$ & 44,5 & 15,2 & 27,6 & 32,6 & 50,9 \\
\hline & Más de 30 & 0,7 & 1,2 & 3,2 & 1,4 & $*$ \\
\hline \multirow{2}{*}{$\begin{array}{l}\text { CICLO } \\
\text { DE VIDA }\end{array}$} & $\begin{array}{l}\text { Vive } \\
\text { en pareja }\end{array}$ & 15,9 & 9,4 & 17,6 & 14,5 & 27,3 \\
\hline & Tiene hijos & 3,6 & 1,6 & 1,5 & 2,5 & 11,3 \\
\hline \multirow{5}{*}{ RELIGIOSIDAD } & $\begin{array}{l}\text { Católico } \\
\text { practicante }\end{array}$ & 7 & 41,4 & 3 & 15,5 & 9,5 \\
\hline & $\begin{array}{l}\text { Católico no } \\
\text { practicante }\end{array}$ & 27,2 & 44,2 & 2,8 & 26,2 & 40,6 \\
\hline & $\begin{array}{l}\text { Creyente } \\
\text { de otra religión }\end{array}$ & 1,2 & 1,3 & 3 & 1,6 & 4,4 \\
\hline & No creyente & 59,5 & 11 & 90,5 & 53,4 & 43,3 \\
\hline & $\mathrm{NS} / \mathrm{NC}$ & 5,2 & 2,1 & 0,8 & 3,3 & 2,2 \\
\hline
\end{tabular}




\begin{tabular}{|c|c|c|c|c|c|c|}
\hline & & Socialistas & NNGG & Comunistas & $\begin{array}{c}\text { Total } \\
\text { jóvenes } \\
\text { militantes }\end{array}$ & $\begin{array}{c}\text { Población } \\
\text { juvenil }\end{array}$ \\
\hline \multirow{7}{*}{$\begin{array}{l}\text { NIVEL } \\
\text { FORMATIVO }\end{array}$} & $\begin{array}{l}\text { Primarios y } \\
\text { Secundarios }\end{array}$ & 7,6 & 4 & 10,7 & 7,3 & 4,8 \\
\hline & Bachiller & 24,7 & 35,7 & 38,3 & 30,8 & 53,1 \\
\hline & FPI y FPII & 17,6 & 17,4 & 9,3 & 15,6 & 23,4 \\
\hline & Universitarios & 31,4 & 34,7 & 26,3 & 31,2 & 10,5 \\
\hline & Máster & 17,3 & 7,8 & 13,9 & 13,9 & 10,9 \\
\hline & Doctorado & 1,3 & 0,4 & 1,2 & 1,1 & 0,1 \\
\hline & $\mathrm{NS} / \mathrm{NC}$ & 0,1 & 0 & 0,2 & 0,1 & 0,2 \\
\hline \multirow{9}{*}{ SITUACIÓN } & Estudia & 34,2 & 43,5 & 48,6 & 37,5 & 26,2 \\
\hline & Trabaja & 17,3 & 8,6 & 14,7 & 14,2 & 48,7 \\
\hline & Estudia y trabaja & 36,1 & 39,5 & 28,6 & 37,2 & - \\
\hline & Parado & 6,3 & 3,1 & 4,6 & 5,1 & 20,1 \\
\hline & $\begin{array}{l}\text { Busca primer } \\
\text { empleo }\end{array}$ & 4,7 & 4,2 & 2,5 & 4,6 & 3,6 \\
\hline & $\begin{array}{l}\text { Trabajo } \\
\text { domestico }\end{array}$ & 0,8 & 0 & 0,3 & 0,5 & 1,3 \\
\hline & $\begin{array}{l}\text { Voluntariado } \\
\text { social }\end{array}$ & 0,4 & 0,7 & 0,3 & 0,5 & $0,1^{* *}$ \\
\hline & No puede trabajar & 0,1 & 0 & 0 & 0,1 & \\
\hline & NS/NC & 0,2 & 0,4 & 0,5 & 0,3 & - \\
\hline \multirow{8}{*}{$\begin{array}{l}\text { LIBROS } \\
\text { EN CASA }\end{array}$} & Menos de 10 & 1,8 & 1,7 & 1,5 & 1,7 & n.d. \\
\hline & De 11 a 20 & 5,7 & 4,7 & 5,1 & 5,3 & n.d. \\
\hline & De 21 a 50 & 13,1 & 14,1 & 13,4 & 13,5 & n.d. \\
\hline & De 51 a 75 & 13,1 & 12,8 & 10,6 & 12,5 & n.d. \\
\hline & De 76 a 100 & 14,7 & 13,5 & 11,4 & 13,6 & n.d. \\
\hline & De 101 a 200 & 15,7 & 16,3 & 23 & 17,5 & n.d. \\
\hline & Más de 200 & 33,3 & 32,8 & 33,1 & 33,1 & n.d. \\
\hline & $\mathrm{NS} / \mathrm{NC}$ & 2,6 & 4,1 & 2 & 2,9 & n.d. \\
\hline$(\mathrm{N})$ & & 900 & 499 & 410 & 1809 & 1009 \\
\hline
\end{tabular}

* La encuesta CIS 3145 solo se realizó a población mayor de 18 años de edad. Para el análisis se utiliza la población con una edad menor de 31 ańos.

** Entendemos que la opción de respuesta «otra situación» en la encuesta 3145 es asimilable a las opciones «no puede trabajar» o «voluntariado social» de nuestro cuestionario.

N.d. = dato no disponible.

Fuente: elaboración propia a partir de encuesta a jóvenes militantes (2016) y CIS 3145 (2016). 
El porcentaje de jóvenes que conviven en pareja es bastante más pronunciado en el conjunto de la sociedad espańola: casi el doble que entre los militantes de las organizaciones juveniles de los partidos políticos. Las dos formaciones situadas a la izquierda presentan un porcentaje considerablemente mayor que NNGG, donde solo uno de cada diez miembros vive en pareja. La presencia de hijos es escasa en los tres grupos, con un porcentaje un poco más elevado entre los socialistas. La comparación con la población juvenil total denota la menor natalidad de los jóvenes militantes. La explicación de esta situación puede venir de los efectos del ciclo de vida derivados del hecho de que más de un $65 \%$ tiene menos de 25 años o es un efecto derivado del coste familiar que supone la militancia.

La religión, como ya hemos apuntado, supone una fractura entre las fuerzas políticas. Los militantes de las formaciones situadas a la izquierda se consideran muy mayoritariamente como no creyentes, y asciende este sentimiento a más de un $90 \%$ entre los comunistas. Los jóvenes socialistas también muestran su distanciamiento de la religión católica: casi un $60 \%$ se consideran no creyentes y más de un $25 \%$ católicos no practicantes. Se trata de porcentajes similares a los encontrados a principios de los ańos ochenta del pasado siglo para el conjunto del PSOE (Tezanos, 1981: 141). Los miembros de NNGG se declaran en un $85 \%$ católicos, entre los que el $40 \%$ son católicos practicantes. En las tres formaciones, los creyentes de otras religiones son minoritarios o casi inexistentes. Las diferencias entre los jóvenes militantes y la población juvenil son también observables. El grueso de jóvenes españoles se divide entre católicos no practicantes y no creyentes, 40,6\% y 43,3\% respectivamente.

Una amplia mayoría de los jóvenes militantes encuestados tiene finalizados sus estudios de bachillerato o universitarios: entre ambos constituyen el $55 \%$ entre los socialistas; el $64 \%$ entre los militantes vinculados a IU, y el $70 \%$ en $\mathrm{NNGG}^{11}$. Destaca la gran proporción de militantes con estudios universitarios finalizados: más del $40 \%$ en los tres casos, incluso el $50 \%$ entre los jóvenes socialistas. A pesar de que el nivel formativo de la sociedad española ha experimentado un alza gracias a las políticas educativas, las diferencias entre los militantes y la población joven en general persisten entre ambos grupos, tal y como apunta la literatura. El nivel de estudios, por tanto, constituye un elemento diferenciador entre los jóvenes militantes y la juventud española en su conjunto, sobre todo a tenor de la proporción de estudios universitarios completados. Estas diferencias han ayudado a explicar la competencia política y su percepción (Gaxie, 1977; Recchi, 1997; Barberà et al., 2002).

En cuanto a la actividad a la que dedican su tiempo, la mayoría de los jóvenes militantes estudia o compagina esta actividad formativa con una actividad laboral. Ambas situaciones suponen más del $70 \%$ en las tres fuerzas políticas, que mantienen

11. En este punto es importante recordar que son estudios finalizados y que los miembros de NNGG y de IU son más jóvenes y se encuentran en su mayoría por debajo de los 24 años. 
valores muy similares. La comparación con la población juvenil en su conjunto arroja diferencias entre ambos grupos de jóvenes ${ }^{12}$. El trabajo de Barberà et al., (2002) ya señalaba la menor actividad laboral de la población juvenil catalana frente a los jóvenes delegados; esta era, a su vez, mucho más alta entre los delegados de las organizaciones juveniles que entre los jóvenes militantes. Sus datos, al igual que los nuestros, vienen condicionados por la introducción de «estudia y trabaja» como opción de respuesta, que supone un $21 \%$ entre los jóvenes delegados y $37 \%$ entre los militantes.

El número de libros en casa se utiliza como indicador del estatus socioeconómico o de clase social (Torney-Purta et al., 2001; Wolbrecht y Campbell, 2007). A la luz de los datos presentados en la tabla 1 , se puede afirmar que no hay diferencias significativas entre los tres grupos analizados, que presentan valores altos en todos los casos. Esto nos hace pensar que provienen de familias de clase social media, media-alta o alta. Esta homogeneidad indica que los jóvenes militantes proceden de ambientes muy similares en términos de estatus socioeconómico y confirmaría las hipótesis de la transversalidad de bases sociales de los miembros de las formaciones políticas.

En cuanto a su perfil político (tabla 2), en términos generales los jóvenes militantes completan su afiliación a la agrupación juvenil en la franja de edad de 18 a 24 años. Destaca sobre todo el caso de NNGG, donde más de un $70 \%$ de sus miembros iniciaron su militancia en ese intervalo de edad. A pesar de esto, el porcentaje de jóvenes que comienzan su militancia en las agrupaciones juveniles antes de alcanzar la mayoría de edad representa aproximadamente un tercio del total de jóvenes militantes. Este dato seńala que las organizaciones juveniles nutren su cantera con miembros bajo figuras como la de simpatizante, con el objetivo de tener mayor presencia en la sociedad, mayor peso en el partido político y ejercer su principal función, que es la de reclutar y socializar nuevos miembros.

Un alto porcentaje de jóvenes militantes declara haber desempeñado el rol de delegado o subdelegado en el aula en algún momento de su período formativo. Los porcentajes para las diferentes organizaciones juveniles son altos: entre los socialistas llegan al $80 \%$, y en las organizaciones juveniles vinculadas a Izquierda Unida son dos de cada tres miembros. La representación del colectivo estudiantil sin llegar a alcanzar la condición de delegado o subdelegado también ha sido ejercida en un nivel significativo, aunque con unas tasas más moderadas. Esta figura también varía entre las diversas formaciones, que alcanza a más de un $30 \%$ de sus miembros, e incluso se llega a casi la mitad de los miembros en el caso de las formaciones políticas vinculadas a IU.

12. En todo caso, hay que ser cautos en esta afirmación, ya que la opción «estudia y trabaja» no está contemplada en el cuestionario del CIS 3145. 
TABLA 2.

Afiliación, activismo asociativo y Carrera política (EN \% DE «Sí»)

\begin{tabular}{lcccc}
\hline & Socialistas & NNGG & Comunistas & $\begin{array}{c}\text { Total jóvenes } \\
\text { militantes }\end{array}$ \\
\hline EDAD AL AFILIARSE & & & & \\
\hline $14-18$ & 29,5 & 27,2 & 36,1 & 30,4 \\
\hline $18-24$ & 58,3 & 71,4 & 56,8 & 61,5 \\
\hline $25-30$ & 12,2 & 1,4 & 7,1 & 8,1 \\
\hline REPRESENTACIÓN & & & & \\
\hline $\begin{array}{l}\text { Delegado y/o } \\
\text { subdelegado }\end{array}$ & 80 & 76,2 & 68,5 & 76,3 \\
\hline Representante estudiantil & 38,7 & 40,7 & 44,6 & 40,6 \\
\hline ASOCIACIONISMO & & & & 58,2 \\
\hline Estudiantes & 55,2 & 50,3 & 74,4 & 57,4 \\
\hline Juvenil & 55,4 & 54,5 & 65,6 & 50,5 \\
\hline Cultural & 50,2 & 49,1 & 52,7 & \\
\hline CARRERA POLÍTICA & & & & 52,8 \\
\hline Ejecutiva & 57,6 & 47,1 & 49,3 & 9,3 \\
\hline Candidato & 34,3 & 32,1 & 27,3 & 1809 \\
\hline Cargo público & 12,1 & 8,2 & 4,6 & 410 \\
\hline (N) & 900 & 499 & & \\
\hline & & & & \\
\hline
\end{tabular}

Fuente: elaboración propia a partir de encuesta a jóvenes militantes (2016).

La vinculación con la sociedad civil también está presente entre los jóvenes militantes: más del $75 \%$ pertenece a alguna asociación fuera de su agrupación política. A pesar de ser transversales, los valores más altos los encontramos entre los miembros de las organizaciones juveniles situadas a la izquierda donde, en el caso de los vinculados a IU, llegan casi al $90 \%$ y más de un $35 \%$ de ellos pertenece a asociaciones de los tres tipos. Estos datos son superiores a los encontrados en el trabajo sobre los delegados congresuales de Barberà et al. (2002) y contrastan con los trabajos que señalan un debilitamiento en la vinculación de los partidos políticos con la sociedad civil (Scarrow, 2000; Webb et al., 2002).

Por último, la tabla se completa con la experiencia y perfil político de los jóvenes miembros de las organizaciones juveniles. En cuanto a la carrera en la formación política, la mitad de ellos ha tenido o tiene en la actualidad una posición ejecutiva en la organización juvenil, sin que se observen grandes diferencias entre las formaciones, lo que supone una alta retribución de la militancia. Con estos incentivos selectivos se socializa y forma a los miembros de las organizaciones juveniles en la cultura de la 
formación política al hacerles conocedores de los ritos informales y procedimientos formales (Bargel, 2008). Esta experiencia en la estructura ejecutiva de la organización juvenil está relacionada con unos inicios más tempranos en posiciones políticas electas y con una carrera política de más éxito que la de aquellos políticos que no han pasado por la sección juvenil del partido (Recchi, 1997; Hooghe et al., 2004). En este ámbito, antes de la obtención de un mandato representativo se debe concurrir como candidato a un cargo de representación política en algún nivel de los ámbitos de gobierno (local, autonómico, nacional y europeo). Un tercio de los encuestados señalan que ha concurrido como candidato, con porcentajes muy similares entre las tres formaciones, aunque es un poco mayor entre los miembros socialistas. De ellos, el porcentaje que ha sido cargo público varía en función de los apoyos electorales que tienen cada una de las formaciones políticas de cabecera, como era lo esperado. Este motivo hace que el $12 \%$ de los jóvenes socialistas y el 8,2\% de los de NNGG hayan resultado electos, por lo que el porcentaje es menor entre los comunistas. En general, tres de cada diez jóvenes militantes han sido candidatos, de los cuales solo uno ha llegado a desempeñar un cargo de elección pública.

\section{Exploración multivariante}

El análisis descriptivo previo ofrece una visión general de los jóvenes militantes de las organizaciones juveniles de los partidos políticos, pero no permite afirmar si las características analizadas son determinantes en ese grupo o son transversales a los miembros de las diferentes fuerzas políticas. Para determinar la influencia de las diferentes variables contempladas con anterioridad, se ha recurrido a un modelo de regresión logística en el que se contempla como variable dependiente la pertenencia a una organización juvenil (1) frente a la militancia en las otras fuerzas políticas $(0)^{13}$. Las tablas 3, 4 y 5 presentan los resultados de tres modelos para cada una de las variables dependientes. El primero de ellos incluye las variables de carácter socioeconómico y demográfico incluidas en la tabla 1; el segundo hace lo propio con las variables de experiencia y carrera política presentes en la tabla 2. Por último, un tercero recoge el conjunto de variables ${ }^{14}$. Atendiendo al R2 de Nagelkerke, el poder explicativo del modelo completo (3) es muy superior a la varianza explicada por el sociodemográfico y el político. Comparando entre formaciones se observa que el poder explicativo es mayor en el caso de NNGG. Esto indica que sus miembros

13. La configuración resultante es de socialistas frente al resto (NNGG y comunistas), NNGG frente al resto (socialistas y comunistas), y miembros de IU frente al resto (NNGG y socialistas). Las variables independientes también se definen de forma binaria $(0,1)$.

14. Sobre la bondad del modelo, hay que apuntar que el chi-cuadrado en la prueba ómnibus es significativo. En todas las regresiones logísticas ejecutadas. La significación es de 0,00 lo que indica que el modelo ayuda a explicar las diferencias. 
presentan un perfil más homogéneo y menos diverso que en las formaciones de izquierda. Los diferentes modelos clasifican entre el 57,8 y el 80,8 de los casos, lo que nos permite su aceptación.

Como se puede desprender de la observación de las tres tablas, las variables tratadas muestran algún tipo de influencia que nos ayuda a componer las características de los militantes de cada formación. La excepción es el nivel formativo, que no marca ninguna diferencia en los perfiles de las tres formaciones, lo que nos permite afirmar que la composición de las diferentes organizaciones presenta una similar distribución en cuanto a la formación educativa completada por sus miembros. Variables como la participación en asociaciones de estudiantes o juveniles también carecen de valor discriminante entre los miembros de las formaciones políticas juveniles analizadas. A tenor de la literatura sobre participación política, la membresía en este tipo de asociaciones se constituye como un elemento diferenciador entre los miembros de los partidos y la población, pero, a pesar de su destacado papel, no establece diferencias entre los miembros de las diferentes organizaciones juveniles partidistas. En cambio, la membresía en asociaciones culturales sílas presenta. Entre los miembros de asociaciones culturales es más probable militar en NNGG, y no en las formaciones socialistas. Por último, la homogeneidad también se presenta en la candidatura. Los diferentes análisis de regresión no muestran relaciones significativas entre los miembros de las diferentes formaciones y esta variable.

El resto de variables señalan diferencias entre los militantes con diversos grados de importancia. El poder divergente de las variables situación profesional y estatus socioeconómico es limitado, ya que la presencia de diferencias se observa solo en alguna de las opciones de respuesta. En cambio, el análisis señala la presencia de diferencias entre formaciones en género, religión, vivir en pareja e hijos, la edad de afiliación, el haber sido delegado y representante estudiantil, y el desempeño de cargos ejecutivos y públicos de representación.

Una de las que ejercen una mayor discriminación entre los tres grupos es la religión, determinante en el perfil de los militantes de NNGG, donde es más probable encontrar a jóvenes creyentes. Entre los militantes socialistas y comunistas es mucho más probable encontrar a los no creyentes. Las variables que marcan el clico de vida, pareja e hijos, también son relevantes, pero con un efecto menor que el observado en la religión, y discriminan entre las formaciones de izquierda. Vivir en pareja e hijos presentan una relación divergente entre las formaciones. La cohabitación se presenta como significativa entre los afiliados comunistas, en los que además es menos probable tener hijos. Esta característica muestra su efecto entre los miembros de las fuerzas políticas socialistas. Del primer modelo, el género y la edad completan las variables que establecen diferencias. Es más probable encontrar mujeres entre los miembros socialistas y, en menor medida, entre los comunistas. Es más probable encontrar a los más mayores en las filas de las formaciones comunistas, y los más jóvenes en las filas de NNGG.

El poder explicativo del segundo modelo es más limitado, el R2 es menor y algunas de las variables pierden su poder explicativo al incluir las variables sociodemográficas. A 
pesar de esto, variables como la edad de afiliación, el haber sido delegado o representante estudiantil, el haber sido miembro de la ejecutiva o cargo público, se vinculan con los miembros de las diferentes organizaciones políticas juveniles. En aquellos jóvenes que se han afiliado entre los 25 y 30 años a la organización es más probable que estén vinculados con la formación socialista, y entre los que llegaron de 18 a 24 años con NNGG. La participación como «dirigentes», ya sea delegados de clase o representantes del colectivo estudiantil en el ámbito educativo, también señala diferentes siluetas. Encontramos que este tipo de participación es significativa en las formaciones de izquierda. Los miembros de las formaciones socialistas se decantan en mayor medida por la actividad de delegado o subdelegado, mientras que los comunistas tienen o han tenido cargos de representación estudiantil.

En términos de carrera política también hay diferencias y similitudes. Los jóvenes militantes presentan diferencias significativas en la ocupación de posiciones en la ejecutiva de la organización juvenil y en posiciones de elección pública. La presencia positiva de estas dos variables es significativa para los miembros socialistas; por el contrario, aparecen en un sentido inverso entre los miembros de NNGG para el desempeño de posiciones ejecutivas y en las formaciones vinculadas a IU para posiciones públicas.

TABLA 3.

REGRESIÓN LOGÍSTICA PARA LOS JÓVENES SOCIALISTAS

\begin{tabular}{|c|c|c|c|c|c|c|}
\hline & \multicolumn{2}{|c|}{ Modelo 1} & \multicolumn{2}{|c|}{ Modelo 2} & \multicolumn{2}{|c|}{ Modelo 3} \\
\hline & B & Exp. B) & B & Exp. B) & B & Exp. B) \\
\hline Género $(1=$ mujer $)$ & $0,334^{* * *}$ & 1,396 & & & $0,349^{* * *}$ & 1,418 \\
\hline \multicolumn{7}{|l|}{ Edad (ref. 14-17) } \\
\hline Edad 18- 24 & $-0,723^{* *}$ & 0,486 & & & $-0,759^{* *}$ & 0,468 \\
\hline Edad 25-30 & 0,339 & 1,403 & & & 0,118 & 1,126 \\
\hline Edad más de 30 & $-1,662^{* *}$ & 0,190 & & & $-1,927^{* * *}$ & 0,146 \\
\hline Pareja & $-0,249$ & 0,780 & & & $-0,217$ & 0,805 \\
\hline Hijos & $0,765^{*}$ & 2,149 & & & $0,636+$ & 1,889 \\
\hline No creyente & $0,466^{* * *}$ & 1,593 & & & $0,465^{* * *}$ & 1,591 \\
\hline \multicolumn{7}{|c|}{ Estudios (Ref. básicos) } \\
\hline Medios & 0,084 & 1,088 & & & 0,101 & 1,107 \\
\hline Universitarios & 0,063 & 1,065 & & & 0,063 & 1,065 \\
\hline
\end{tabular}

Situación (Ref. estudia y trabaja)

\begin{tabular}{lcccc}
\hline Estudia & $-0,178$ & 0,837 & $-0,170$ & 0,844 \\
\hline Trabaja & 0,016 & 1,016 & $-0,026$ & 0,975 \\
\hline Otra situación & 0,297 & 1,346 & 0,262 & 1,300 \\
\hline
\end{tabular}


$\ldots / \ldots$

\begin{tabular}{|c|c|c|c|c|c|c|}
\hline & \multicolumn{2}{|c|}{ Modelo 1} & \multicolumn{2}{|c|}{ Modelo 2} & \multicolumn{2}{|c|}{ Modelo 3} \\
\hline & B & Exp. B) & B & Exp. B) & B & Exp. B) \\
\hline \multicolumn{7}{|l|}{ Libros (Ref. 0-50) } \\
\hline Libros 51-100 & 0,116 & 1,123 & & & 0,119 & 1,126 \\
\hline Libros 101-200 & $-0,293^{+}$ & 0,746 & & & $-0,287+$ & 0,751 \\
\hline Libros más de 200 & $-0,067$ & 0,935 & & & $-0,026$ & 0,974 \\
\hline \multicolumn{7}{|l|}{$\begin{array}{l}\text { Edad afiliación } \\
\text { (Ref. 14-17) }\end{array}$} \\
\hline Afiliación 18-24 & & & 0,025 & 1,026 & 0,055 & 1,056 \\
\hline Afiliación 25-30 & & & $1,297^{* * *}$ & 3,657 & $0,740^{* *}$ & 2,096 \\
\hline \multicolumn{7}{|l|}{ Representación } \\
\hline Delegado & & & $0,528^{* * *}$ & 1,695 & $0,590^{* * *}$ & 1,805 \\
\hline Estudiantil & & & $-0,211^{*}$ & 0,810 & $-0,165$ & 0,847 \\
\hline \multicolumn{7}{|l|}{ Asociacionismo } \\
\hline Estudiantes & & & $-0,058$ & 0,944 & $-0,147$ & 0,863 \\
\hline Juvenil & & & $-0,191$ & 0,826 & $-0,133$ & 0,875 \\
\hline Cultural & & & $-0,474^{* * *}$ & 0,622 & $-0,387^{*}$ & 0,679 \\
\hline \multicolumn{7}{|l|}{ Carrera política } \\
\hline Ejecutiva & & & $0,406^{* * *}$ & 1,501 & $0,304^{* *}$ & 1,355 \\
\hline Candidato & & & $-0,116$ & 0,891 & $-0,174$ & 0,840 \\
\hline Cargo público & & & $0,602^{* *}$ & 1,826 & $0,503^{*}$ & 1,654 \\
\hline Constante & 0,011 & 1,011 & $-0,532^{* * *}$ & 0,588 & $-0,407$ & 0,665 \\
\hline-2 log de la verosimilitud & \multicolumn{2}{|c|}{2330,704} & \multicolumn{2}{|c|}{2392,291} & \multicolumn{2}{|l|}{2270,338} \\
\hline R2 de Cox y Snell & \multicolumn{2}{|c|}{0,093} & \multicolumn{2}{|c|}{0,062} & \multicolumn{2}{|c|}{0,123} \\
\hline R2 de Nagelkerke & \multicolumn{2}{|c|}{0,124} & \multicolumn{2}{|c|}{0,082} & \multicolumn{2}{|c|}{0,164} \\
\hline
\end{tabular}

$\left[{ }^{+} p \leq\left. .100\right|^{*} p \leq\left. .050\right|^{* *} p \leq\left. .010\right|^{* * *} p \leq .001\right]$

Fuente: elaboración propia a partir de encuesta a jóvenes militantes (2016).

TABLA 4.

Regresión lOGÍstica PARA NNGG

\begin{tabular}{lcccccc}
\hline & \multicolumn{2}{c}{ Modelo 1 } & \multicolumn{2}{c}{ Modelo 2 } & \multicolumn{2}{c}{ Modelo 3 } \\
\hline & B & Exp. B) & B & Exp. B) & B & Exp. B) \\
\hline Género (1=mujer) & $-0,161$ & 0,851 & & & $-0,150$ & 0,861 \\
\hline Edad (ref. 14-17) & & & & & \\
\hline Edad 18- 24 & $1,924^{* * *}$ & 6,848 & & & $1,947^{* * *}$ & 7,011 \\
\hline Edad 25-30 & 0,437 & 1,548 & & & 0,695 & 2,004 \\
\hline
\end{tabular}


$\ldots / \ldots$

\begin{tabular}{|c|c|c|c|c|c|c|}
\hline & \multicolumn{2}{|c|}{ Modelo 1} & \multicolumn{2}{|c|}{ Modelo 2} & \multicolumn{2}{|c|}{ Modelo 3} \\
\hline & $\mathbf{B}$ & Exp. B) & $\mathbf{B}$ & Exp. B) & B & Exp. B) \\
\hline Edad más de 30 & $1,514^{*}$ & 4,546 & & & $1,761^{*}$ & 5,815 \\
\hline Pareja & $-0,179$ & 0,836 & & & $-0,220$ & 0,803 \\
\hline Hijos & $-0,171$ & 0,843 & & & $-0,057$ & 0,945 \\
\hline No creyente & $-2,970^{* * *}$ & 0,051 & & & $-2,970^{* * *}$ & 0,51 \\
\hline \multicolumn{7}{|c|}{ Estudios (Ref. básicos) } \\
\hline Medios & 0,479 & 1,614 & & & 0,458 & 1,581 \\
\hline Universitarios & 0,491 & 1,635 & & & 0,458 & 1,581 \\
\hline \multicolumn{7}{|c|}{ Situación (Ref. estudia y trabaja) } \\
\hline Estudia & $-0,175$ & 0,840 & & & $-0,156$ & 0,856 \\
\hline Trabaja & $-0,460^{*}$ & 0,631 & & & $-0,440+$ & 0,644 \\
\hline Otra situación & $-0,471^{+}$ & 0,624 & & & $-0,420+$ & 0,657 \\
\hline \multicolumn{7}{|l|}{ Libros (Ref. 0-50) } \\
\hline Libros $51-100$ & 0,187 & 1,205 & & & 0,158 & 1,172 \\
\hline Libros 101-200 & 0,211 & 1,235 & & & 0,191 & 1,210 \\
\hline Libros más de 200 & $0,368^{*}$ & 1,445 & & & $0,304+$ & 1,356 \\
\hline
\end{tabular}

\section{Edad afiliación (Ref.}

14-17)

\begin{tabular}{|c|c|c|c|c|c|}
\hline Afiliación 18-24 & & $0,270^{*}$ & 1,310 & $-0,037$ & 0,964 \\
\hline Afiliación 25-30 & & $-2,025^{* * *}$ & 0,132 & $-1,470^{* * *}$ & 0,230 \\
\hline \multicolumn{6}{|l|}{ Representación } \\
\hline Delegado & & $-0,027$ & 0,974 & $-0,356^{*}$ & 0,701 \\
\hline Estudiantil & & $-0,055$ & 0,947 & 0,058 & 1,060 \\
\hline \multicolumn{6}{|l|}{ Asociacionismo } \\
\hline Estudiantes & & 0,59 & 1,061 & 0,153 & 1,165 \\
\hline Juvenil & & 0,094 & 1,098 & 0,147 & 1,158 \\
\hline Cultural & & $0,557^{* * *}$ & 1,745 & 0,220 & 1,246 \\
\hline \multicolumn{6}{|l|}{ Carrera política } \\
\hline Ejecutiva & & $-0,361^{* *}$ & 0,697 & $-0,233$ & 0,792 \\
\hline Candidato & & 0,110 & 1,116 & 0,179 & 1,192 \\
\hline Cargo público & & $-0,100$ & 0,905 & 0,048 & 1,049 \\
\hline Constante & $-1,793^{* * *}$ & $-0,996^{* * *}$ & 0,370 & $-1,555^{* *}$ & 0,211 \\
\hline-2 log de la verosimilitud & 1472,035 & \multicolumn{2}{|c|}{2035,366} & \multicolumn{2}{|c|}{1444,744} \\
\hline R2 de Cox y Snell & 0,305 & \multicolumn{2}{|c|}{0,051} & \multicolumn{2}{|c|}{0,316} \\
\hline R2 de Nagelkerke & 0,441 & \multicolumn{2}{|c|}{0,074} & \multicolumn{2}{|c|}{0,456} \\
\hline
\end{tabular}

$\left.{ }^{+} p \leq\left. .100\right|^{*} p \leq\left. .050\right|^{* *} p \leq\left. .010\right|^{* * *} p \leq .001\right]$

Fuente: elaboración propia a partir de encuesta a jóvenes militantes (2016). 
TABLA 5.

REgRESIÓN LOGÍSTICA PARA LOS JÓVENES COMUNISTAS

\begin{tabular}{|c|c|c|c|c|c|c|}
\hline & \multicolumn{2}{|c|}{ Modelo 1} & \multicolumn{2}{|c|}{ Modelo 2} & \multicolumn{2}{|c|}{ Modelo 3} \\
\hline & B & Exp. B) & $\mathrm{B}$ & Exp. B) & B & Exp. B) \\
\hline Género (1=mujer) & $-0,409^{* *}$ & 0,665 & & & $-0,415^{* *}$ & 0,661 \\
\hline \multicolumn{7}{|l|}{ Edad (ref. 14-17) } \\
\hline Edad 18- 24 & $-0,056$ & 0,945 & & & $-0,050$ & 0,951 \\
\hline Edad 25-30 & $-0,358$ & 0,680 & & & -0223 & 0,800 \\
\hline Edad más de 30 & $1,574^{* *}$ & 4,828 & & & $1,787^{* *}$ & 5,972 \\
\hline Pareja & $0,521^{* *}$ & 1,683 & & & $0,497^{* *}$ & 1,644 \\
\hline Hijos & $-1,147^{*}$ & 0,318 & & & $-0,946^{*}$ & 0,388 \\
\hline No creyente & $2,399^{* * *}$ & 11,015 & & & $2,431^{* * *}$ & 11,375 \\
\hline \multicolumn{7}{|c|}{ Estudios (Ref. básicos) } \\
\hline Medios & $-0,393$ & 0,675 & & & $-0,408$ & 0,665 \\
\hline Universitarios & $-0,420$ & 0,657 & & & $-0,419$ & 0,657 \\
\hline \multicolumn{7}{|c|}{$\begin{array}{l}\text { Situación (Ref. estudia } \\
\text { y trabaja) }\end{array}$} \\
\hline Estudia & $0,466^{* *}$ & 1,594 & & & $0,426^{* *}$ & 1,531 \\
\hline Trabaja & 0,325 & 1,384 & & & 0,330 & 1,391 \\
\hline Otra situación & $-0,056$ & 0,945 & & & $-0,018$ & 0,982 \\
\hline \multicolumn{7}{|l|}{ Libros (Ref. 0-50) } \\
\hline Libros $51-100$ & $-0,385^{*}$ & 0,680 & & & $-0,353+$ & 0,703 \\
\hline Libros 101-200 & 0,162 & 1,176 & & & 0,159 & 1,172 \\
\hline Libros más de 200 & $-0,247$ & 0,781 & & & $-0,259$ & 0,772 \\
\hline
\end{tabular}

Edad afiliación (Ref.

14-17)

\begin{tabular}{lcccc}
\hline Afiliación 18-24 & $-0,396^{* *}$ & 0,673 & $-0,051$ & 0,950 \\
\hline Afiliación 25-30 & $-0,355$ & 0,701 & $-0,291$ & 0,747 \\
\hline Representación & & & & \\
\hline Delegado & $-0,692^{* * *}$ & 0,501 & $-0,604^{* * *}$ & 0,546 \\
\hline Estudiantil & $0,353^{* *}$ & 1,424 & $0,258+$ & 1,294 \\
\hline Asociacionismo & & & & \\
\hline Estudiantes & $-0,060$ & 0,942 & 0,104 & 1,014 \\
\hline Juvenil & 0,106 & 1,12 & 0,130 & 1,139 \\
\hline Cultural & 0,005 & 1,005 & 0,286 & 1,331 \\
\hline
\end{tabular}


... $/ \ldots$

\begin{tabular}{|c|c|c|c|c|c|c|}
\hline & \multicolumn{2}{|c|}{ Modelo 1} & \multicolumn{2}{|c|}{ Modelo 2} & \multicolumn{2}{|c|}{ Modelo 3} \\
\hline & B & Exp. B) & B & Exp. B) & B & Exp. B) \\
\hline \multicolumn{7}{|l|}{ Carrera política } \\
\hline Ejecutiva & & & $-0,202$ & 0,817 & $-0,213$ & 0,808 \\
\hline Candidato & & & 0,000 & 1,000 & 0,035 & 1,035 \\
\hline Cargo público & & & $-0,787^{* * *}$ & 0,455 & $-0,863^{* *}$ & 0,422 \\
\hline Constante & $-2,347^{* * *}$ & 0,096 & $-0,551^{* * *}$ & 0,576 & $-1,939^{* * *}$ & 0,144 \\
\hline-2 log de la verosimilitud & \multicolumn{2}{|c|}{1548,237} & \multicolumn{2}{|c|}{1884,260} & \multicolumn{2}{|c|}{1512,278} \\
\hline R2 de Cox y Snell & \multicolumn{2}{|c|}{0,193} & \multicolumn{2}{|c|}{0,028} & \multicolumn{2}{|c|}{0,209} \\
\hline R2 de Nagelkerke & \multicolumn{2}{|c|}{0,294} & \multicolumn{2}{|c|}{0,043} & \multicolumn{2}{|c|}{0,318} \\
\hline
\end{tabular}

$\left[{ }^{+} p \leq\left. .100\right|^{*} p \leq\left. .050\right|^{* *} p \leq\left. .010\right|^{* * *} p \leq .001\right]$

Fuente: elaboración propia a partir de encuesta a jóvenes militantes (2016)

\section{CONCLUSIONES}

En este trabajo se presentan los datos de una encuesta realizada a los miembros de las organizaciones políticas juveniles de las fuerzas políticas que han obtenido representación en la Cámara Baja tras las elecciones estatales de 1986. Con ella se pueden observar bajo un enfoque exploratorio las diferencias y similitudes en las características sociodemográficas y políticas de sus militantes, lo que permite una comparación sistemática entre las formaciones al disponer de un único cuestionario. Además, se han podido comparar las características de estos militantes con respecto al conjunto de los jóvenes españoles. Con este trabajo se llena parte del vacío existente actualmente en Espańa sobre los miembros de las organizaciones juveniles de los partidos políticos y se ofrecen algunos rasgos sobre la composición futura de los partidos políticos.

En general, los miembros de las organizaciones políticas juveniles se alejan de la población general en cuatro de las características observadas. Las organizaciones políticas juveniles analizadas están compuestas en su mayoría por hombres y entre sus miembros priman aquellos con estudios universitarios. La afiliación femenina, a pesar de su documentada evolución positiva, no se ve traducida en la proporción de jóvenes, que debería alcanzar valores cercanos al $50 \%$. Esta situación refleja la presencia de un gender gap, traducido en una lenta incorporación de la mujer a la vida política. En su conjunto, los niveles de instrucción entre los miembros de las organizaciones juveniles partidistas son superiores a la media nacional, algo ampliamente constatado para el conjunto de los miembros de los partidos políticos y de las elites políticas. Vivir en pareja y tener hijos suponen, además de un componente distintivo en la configuración del perfil de los miembros de las diferentes formaciones, un elemento diferenciador con la población juvenil. Como se ha visto, el número de 
militantes que vive en pareja y que tiene hijos es muy inferior al presente entre los jóvenes de la población general.

En relación con los diferentes perfiles que podemos observar entre las formaciones políticas, no se observan diferencias en el nivel educativo y en la pertenencia a asociaciones estudiantiles y juveniles. Estas tres variables homogenizan los miembros de las diferentes fuerzas políticas. Esto nos indica que el entorno social no es un elemento clave en la definición de la militancia de las diferentes formaciones, que se nutren de miembros procedentes de diferentes niveles. También hay una alta similitud en términos de estatus socioeconómico y situación profesional. Las diferencias entre los miembros de las formaciones se manifiestan en torno al género, la pertenencia a asociaciones culturales y, especialmente, la religión, que se convierte en un elemento distintivo central. Los datos presentados en este trabajo constatan que los miembros de las organizaciones políticas juveniles siguen en gran medida las lógicas esperadas y ofrecen diferentes matices según las características de sus fuerzas políticas de adscripción.

\section{AGRADECIMIENTOS}

El autor agradece las sugerencias y los comentarios de los evaluadores anónimos de este trabajo y que sin duda han contribuido a la mejora del mismo. Se quiere asimismo dar las gracias a los jóvenes que voluntariamente y sin ningún tipo de incentivo material quisieron ceder parte de su tiempo para contestar el cuestionario, así como a la cúpula directiva y staff de las diferentes organizaciones juveniles partidistas por la ayuda prestada para el desarrollo del trabajo de campo.

El proceso de realización de este trabajo ha sido en parte financiado por la Consejería de Innovación, Ciencia y Empresa de la Junta de Andalucía; en primer lugar, a través de la concesión al autor de una beca de formación de personal investigador asociada al proyecto de excelencia P08-SEJ-04032; en segundo lugar, por medio de una estancia de investigación en el Department of Political Science del Trinity College de Dublín.

\section{Referencias}

Abrams, Philip y Alan Little.1965). "The young activist in British Politics», The British JournalofSociology, 16(4):315-333. Disponible en: https://doi.org/10.2307/589159. Alarcón González, Francisco Javier y Sergio Pérez Castaños. 2015. «The political career of members of youth wings", comunicación presentada en el XII Congreso de la Asociación Española de Ciencia Politica, San Sebastián.

Almond, Gabriel y Sidney Verba. 1963. The civic culture: Political attitudes and democracy in five nations. Princeton: Princeton University Press. Disponible en: https:// doi.org/10.1515/9781400874569. 
Argelaguet, Jordi. 2009. «Elementos de cambio y de continuidad en la militancia de ERC (1993- 2004)», Papers, 92: 75-96. Disponible en: https://doi.org/10.5565/ rev/papers/v92n0.708.

Baras, Montserrat, Jordi Argelaguet, Òscar Barberà, Astrid Barrio, Joan Botella y Juan Rodríguez-Teruel. 2004. Els militants dels partits politics a Catalunya. Perfils socials i percepcions polítiques. Barcelona: Institut de Ciències Polítiques i Socials.

Baras, Montserrat, Jordi Argelaguet y Patricia Correa. 2010. «Radiographie des militans des Partis Politiques en Espagne», Pôle Sud, 33: 65-82.

Baras, Montserrat, Oscar Barberà, Astrid Barrio, Patricia Correa y Juan RodríguezTeruel. 2015. "Party membership in Spain and Congress delegates», en Emilie Van Haute y Anika Gauja (eds.), Party Members and Activists. Oxon: Routledge.

Barberà Oscar, Astrid Barrio y Juan Rodríguez-Teruel. 2002. Els militants de les organitzacions politiques juvenils a Catalunya. Barcelona: Diputació de Barcelona.

Bargel, Lucie. 2008. Aux avant-postes. La socialisation au métier politique dans deux organisations de jeunesse de parti Jeunes populaires (UMP) et Mouvement des jeunes socialistes (PS). París : Universidad Paris I Panthéon Sorbonne.

Barrio, Astrid, Juan Rodríguez-Teruel, Oscar Barberà y Montserrat Baras. 2011. "Convention Delegates in Spain: State of the art», comunicación presentada en el workshop The Current State of Party Member Research, Copenhagen.

Botella, Joan, Jordi Capo y Joan Marcet. 1979. «Aproximación a la sociología de los partidos políticos catalanes», Revista de Estudios Políticos, 10: 143-206.

Bruter, Michael y Sarah Harrison. 2009. The future of our democracies: Young party member in Europe. Basingstoke: Palgrave Macmillan.

Cayrol, Roland. 1974. «Les militants du Parti Socialiste, contribution à une sociologie», Projet, 88 : 929-940.

Colomé, Gabriel. 1992a. "Los delegados del Parti desl Socialistes de Catalunya (19821990)", Revista del Centro de Estudios Constitucionales, 12: 25-44.

Colomé, Gabriel. 1992b. «La composicio sociològica dels delegats del VIII Congrès del PSUC a l'Assemblea Fundacional d'IC», Papers, 39: 43-58.

Colomé, Gabriel. 1996. The Leftist parties in Catalonia. IPCS Working Paper 88/1996, Barcelona.

Colomé, Gabriel. 1998. Els delegats del VIII Congrés del PSC. Papers de la Fundació, 106/199X. Barcelona: Fundació Rafael Campalans.

Cross, Willian y Lisa Young. 2004. "The contours of political party membership in Canada», Party Politics, 10 (4): 427-444. Disponible en: https://doi. org/10.1177/1354068804043907.

Cross, Willian y Lisa Young. 2008. «Membership among young party members: The case of the Canadian Liberal Party», Journal of Elections, Public Opinion and Parties, 18(3):257-281.Disponibleen:https://doi.org/10.1080/17457280802227660.

Dalton, Russell. 2005. Citizen Politics: Public Opinion and Political Parties in Advanced Industrial Democracies. Washington: CQ Press.

Dalton, Russell y Martin P. Wattenber. 2000. Parties without Partisans: Political change in advanced industrial democracies. Oxford: New York: Oxford University Press. 
Dogan, Mattei. 1999. «Les professions propices a la carrière politique : Osmoses, Filières et Viviers ", en Michel Offerlé (ed.), La Profession politique, XIXe-Xxe siècles. Paris : Belin.

Duverger, Maurice. 1957 [1951]. Los partidos políticos. México: Fondo de Cultura Económica

Espinoza E. Vicente y Madrid P. Sebastián. 2010. Trayectoria y eficacia policía de los militantes en juventudes politicas. Estudio de la élite politica emergente. Chile: Andros.

Gallagher, Michael y Michael Marsh. 2004. «Party membership in Ireland: The members of Fine Gael», Party Politics, 10 (4): 407- 425. Disponible en: https://doi. org/10.1177/1354068804043906.

Gaxie, Daniel. 1977. «Economie des partis et rétributions du militantisme», Revue Française de Science Politique, 27 (1): 123-154.

García-Albacete, Gema. 2014. Young people's political participation in Western Europe, continuity or generational change. Basingstoke, Hampshire: Palgrave Macmillan. Disponible en: https://doi.org/10.1057/9781137341310.

Gunther, Richard, José Ramón Montero y Juan J. Linz. 2002. Political parties. Old concepts and new challenges. Oxford: Oxford University Pres. Disponible en: https://doi.org/10.1093/0199246742.001.0001.

Hooghe, Marc, Dietlind Stolle y Patrick Stouthuysen. 2004. «Head Start in Politics: The recruitment function of youth organizations of political parties in Belgium (Flanders)», Party Politics, 10 (2): 193-212. Disponible en: https://doi. org/10.1177/1354068804040503.

Katz, Richard y Peter Mair (eds.). 1994. How parties organize: Change and adaptation in party organisations in Western democracies. London: Sage.

Lipset, Seymour Marting y Stein Rokkan. 1967. Party systems and voter alignments. New York: Free Press.

Mair, Peter y Ingrid van Biezen. 2001. «Party membership in 20 European democracies, 1980-2000», Party Politics, 7 (1): 5-21. Disponible en: https://doi.org/10.11 $77 / 1354068801007001001$.

Marcet, Joan. 1984. Convergencia Democrática de Cataluña. Madrid: Centro de Investigaciones Sociológicas.

Méndez Lago, Mónica. 2000. La estrategia organizativa del Partido Socialista Obrero Español (1975-1996). Madrid: Centro de Investigaciones Sociológicas.

Muñoz Armenta, Aldo, Leticia Heras-Gómez y Amalia Pulido Gómez. 2013. «Una aproximación a la militancia partidista en México: el caso de los partidos emergentes», Convergencia, Revista de Ciencias Sociales, 63: 177- 205.

Norris, Pippa y Joni Lovenduski. 1995. Political recruitment: Gender, race, and class in British Parliament. Cambridge: Cambridge University Press.

Pedersen, Karina, Lars Bille, Roger Buch, Jørgen Elklit, Bernhard Hansen y Hans Jørgen Nielsen. 2004. «Sleeping or active partners? Danish Party members at the turn of the millennium», Party Politics, 10: 367-384. Disponible en: https://doi. org/10.1177/1354068804043904. 
Pitarch, Ismael E., Joan Botella, Jordi Capo y Joan Marcet. 1980. Partits i parlamentaris a la Catalunya d'avui (1977- 1979). Barcelona: Edicions 62.

Ramiro Fernández, Luis. 2004. Cambio y adaptación en la izquierda. La evolución del Partido Comunista de Espa-a y de Izquierda Unida (1986-2000). Madrid: Centro de Investigaciones Sociológicas.

Recchi, Etore. 1997. Giovani politici. Padova: Cedam.

Sánchez, Jordi, Gabriel Colomé, Joaquim Colominas, Joan Botella, Jordi Argelaguet, Jesus Navarro y Antoni Font. 1999. Estudis de les elits dels partits politics de Catalunya. Barcelona: Institut de Ciències Polítiques i Socials.

Scarrow, Susan. 1994. "The paradox of enrollment: Assessing the costs and benefits of party memberships», European Journal of Political Research, 25 (1): 41-60. Disponible en: https://doi.org/10.1111/j.1475-6765.1994.tb01200.x.

Scarrow, Susan. 1996. Parties and their members? Organizing for victory in Britain and Germany. Oxford: Oxford University Press. Disponible en: https://doi.org/1 $0.1093 / 0198279183.001 .0001$.

Scarrow, Susan. 2000. «Parties without members? Party organizations in a changing electoral environment», en Russell J. Dalton y Martin P. Wattenberg (eds.), Parties without partisans: Political change in advanced industrial democracies. Oxford: Oxford University Press.

Scarrow, Susan. 2015. Beyond party members. Changing approaches to partisan mobilization. Oxford: Oxford University Press.

Scarrow Susan y Burcu Gezgor. 2010. «Declining memberships, changing members? European political members in new era", Party Politics, 16 (6): 823-843. Disponible en: https://doi.org/10.1177/1354068809346078.

Seyd, Patrick. 1987. The rise and fall of the Labour Left. London: MacMillan Education LTD. Disponible en: https://doi.org/10.1007/978-1-349-18923-6.

Seyd, Patrick y Paul Whiteley. 1992. Labour's grass roots. The politics of party membership. Oxford: Clarendon Press.

Seyd, Patrick y Paul Whiteley. 2002. New Labour's Grassroots: The Transformation of the Labour Party Membership. Basingstoke: Palgrave-Macmillan. Disponible en: https://doi.org/10.1057/9780230599215.

Seyd, Patrick y Paul Whiteley. 2004. «British party members: an overview», Party Politics, 10:355-366.Disponibleen:https://doi.org/10.1177/1354068804043903.

Steed, Robert P., John A. Clark, Lewis Bowman y Charles D. Hadley. 1998. Party organization and activism in the American South. Alabama: University of Alabama Press.

Tezanos, José Félix. 1980. «Radiografía de dos congresos. Una aportación al estudio sociológico de los cuadros políticos del socialismo espańol», Revista Sistema, 35 (3): 79-99.

Tezanos, José Félix. 1981. "Estructura y dinámica de la afiliación socialista en España», Revista de Estudios Politicos, 23: 117-152.

Torney-Purta, Judith, Rainer Lehmann, Hans Oswald y Wolfram Schulz. 2001. Citizenship and education in twenty-eight countries, Civic knowledge and engagement at 
age fourteen. The International Association for the Evaluation of Educational Achievement.

Van Haute, Emilie (ed.). 2011. Party membership in Europe: Exploration into the anthills of party politics. Bruselas: Editions de l'Université de Bruxelles.

Van Haute, Emilie y Anika Gauja. 2015. Party members and activists. Oxon: Routledge.

Verba, Sidney, Norman H. Nie y Jae-on Kim. 1978. Participation and Political equality: A seven- nation comparison. Cambridge: Cambridge University Press.

Verge, Tania. 2007. Partidos y representación política: las dimensiones del cambio en los partidos políticos españoles, 1976-2006. Madrid: Centro de Investigaciones Sociológicas.

Webb, Paul, David Farrel y Ian Holliday. 2002. Political parties in advanced industrial democracies. Oxford: Oxford University Press. Disponible en: https://doi.org/10. 1093/0199240566.001.0001.

Whiteley, Paul y Patrick Seyd. 1996. «Rationality and party activism: Emcompasing test of alternative models of political participation", European Journal of Political Research, 29 (2): 339-371. Disponible en: https://doi.org/10.1111/j.1475-6765.1996. tb00649.x.

Whiteley, Paul y Patrick Seyd. 1998. "The dynamics of party activism in Britain: A spiral of demobilization?», British Journal of Political Studies, 28: 113-137. Disponible en: https://doi.org/10.1017/S000712349800012X.

Whiteley, Paul y Patrick Seyd. 2002. High intensity participation. The dynamics of Party activism in Britain. Ann Arbor: University Michigan. Disponible en: https:// doi.org/10.3998/mpub.14704.

Whiteley, Paul, Patrick Seyd y Antony Billinghurst. 2006. Thrid force politics: Liberal democrats at the grassroots. Oxford: Oxford University Press. Disponible en: https:// doi.org/10.1093/0199242828.001.0001.

Whiteley, Paul, Patrick Seyd y Jeremy Richardson. 1994. True blues: The politics of Conservative Party membership. Oxford: Oxford University Press.

Whiteley, Paul, Patrick Seyd, Jemery Richardson y Paul Bissell. 1994. «Explaining party activism: The case of the British Conservative Party», British Journal of Political Science, 24 (1): 79-94. Disponible en: https://doi.org/10.1017/ S0007123400006797.

Wolbrecht, Cristina y David E. Campbell. 2007. «Female members of Parliament as political role models», American Journal of Political Science, 51 (4): 921-939. Disponible en: https://doi.org/10.1111/j.1540-5907.2007.00289.x.

Ysmal, Colette. 1985. «Elites et leaders», en M. Grawitz, M. y J. Leca (eds.), Traité de science Politique, vol. 3. Paris: PUF.

Presentado para evaluación: 13 de marzo de 2017. Aceptado para publicación: 18 de octubre de 2017. 


\section{FRANCISCO J. ALARCÓN-GONZÁLEZ}

fjalarcon@ugr.es

Profesor sustituto interino (PSI) en el Departamento de Comercialización e Investigación de Mercados en la Universidad de Granada. Previamente profesor del Departamento de Organización de Empresas, Marketing y Sociología en la Universidad de Jaén e investigador en el Departamento de Ciencia Política y de la Administración de la Universidad de Granada. Licenciado en Ciencia Política y Sociología (especialidad de Ciencias Políticas) y licenciado en Investigación y Técnicas de Mercado, ambas por la Universidad de Granada. Licenciaturas cumplimentadas con estancias dentro de diferentes programas de movilidad en la Universidad Libre de Bruselas y en el Escuela Superior de Comercio de Clemont-Ferrand, respectivamente. Diplomado en Estudios Europeos por el Instituto de Estudios Europeos de la Universidad Libre de Bruselas y Diploma de Estudios Avanzados en Ciencia Política por el Departamento de Ciencia Política y de la Administración de la Universidad de Granada. Ha sido investigador visitante en la Università degli Studi di Padova, Sciences Po (Paris), University College Cork y Trinity College de Dublín. 